13.4

\title{
Металлопористые катоды, модифицированные наноуглеродом, с высокой долговечностью для применения в приборах СВЧ
}

\author{
(C) Т.М. Крачковская ${ }^{1}$, Л.А. Мельников ${ }^{2}$, О.Е. Глухова ${ }^{3,4}$, В.В. Шунаев ${ }^{3}$, П.Д. Шалаев ${ }^{1}$ \\ ${ }^{1}$ НПП „Алмаз“, Саратов, Россия \\ ${ }^{2}$ Саратовский государственный технический университет им. Гагарина Ю.А., Саратов, Россия \\ ${ }^{3}$ Саратовский национальный исследовательский государственный университет им. Н.Г. Чернышевского, Саратов, Россия \\ ${ }^{4}$ Первый Московский государственный медицинский университет им. И.М. Сеченова, Москва, Россия \\ E-mail: elektron.t@bk.ru
}

Поступило в Редакцию 27 марта 2020 г.

В окончательной редакции 9 апреля 2020г.

Принято к публикации 10 апреля 2020г.

\begin{abstract}
Представлены результаты расчетов физических и энергетических параметров наноуглеродных структур с компонентами активного вещества металлопористого катода, находящиеся в хорошем согласии с опытом. Экспериментально определено, что модифицированное сульфоаддуктом нанокластеров углерода активное вещество имеет скорость испарения в 1.5 раза ниже, чем типовое. Испытания катодов, модифицированных наноуглеродом, в составе лампы бегущей волны космического назначения показали их долговечность $1740800 \mathrm{~h}$ при токоотборе $0.645 \mathrm{~A} / \mathrm{cm}^{2}$.
\end{abstract}

Ключевые слова: углеродные нанокластеры, металлопористый катод, Астрален®, Углерон®, долговечность, приборы СВЧ.

DOI: 10.21883/PJTF.2020.13.49593.18315

Надежность и долговечность, а также стабильность электрических характеристик электровакуумных приборов, требования к которым существенно возросли в настоящее время, в значительной степени определяются эмиссионной надежностью и долговечностью катодов, т.е. эмиссионной способностью катода и ее стабильностью в процессе работы. Эмиссионная способность и долговечность катода обусловлены как внутренними, так и внешними факторами.

Внутренними факторами, определяющими потенциально возможные эмиссионные свойства катода и его типовую долговечность, являются состав и скорость испарения активного вещества, состав и пористость губки, чистота материалов катодного узла, режим работы.

Благоприятными внешними условиями служат, во-первых, высокий вакуум и отсутствие отравляющих катод газов непосредственно в вакуумном объеме оболочки прибора; во-вторых, отсутствие загрязнений на поверхности электродов прибора, способных под действием тепловых и электрических (токовых) нагрузок выделяться в вакуумный объем и отравлять катод; в-третьих, отсутствие легкораспыляющихся материалов во внутриламповой арматуре, которые могут при напылении на катод приводить к его необратимому отравлению; отсутствие пробоев между электродами (особенно между катодом и другими электродами), приводящих к разрушению катода.

Обеспечение первых двух из перечисленных условий в значительной степени зависит от способов и режимов обработки прибора при откачке и тренировке, от способов предварительной механической, термической и химической обработки и очистки внутриламповых элек- тродов, деталей и узлов, а также от физико-химических свойств конструкционных материалов внутриламповой арматуры. Последние условия главным образом зависят от физико-химических свойств конструкционных материалов и методов предварительной обработки их перед сборкой, которые в достаточной степени описаны в литературе, например в работе [1].

Также известны конструкторские предложения по повышению долговечности катодов, связанные с увеличением запаса активного вещества: так называемый катод с подпитывающей камерой [2]. Недостатком такой конструкции является сложность изготовления, и, если бы удалось снизить скорость испарения активного вещества в рамках однослойной матрицы металлопористого катода (МПК) с сохранением необходимого уровня эмиссии, это было бы более надежно. В рамках данного направления в [3] были исследованы эмиссионные свойства катодов с добавлением металлов платиновой группы (Os, $\mathrm{Ru}$ и др.) в состав металлической матрицы МПК. Полученные результаты выглядят перспективными с точки зрения повышения долговечности, но по эмиссионной способности совпадают с результатами испытаний МПК с покрытой теми же металлами эмитирующей поверхностью. Кроме того, для таких конструкций встает вопрос экономичности изготовления катодов ввиду увеличения расхода драгметаллов. Для МПК с покрытием на эмитирующей поверхности, которые в основном и применяются в настоящее время, существует также проблема сохранения состава покрытия в процессе эксплуатации. Со временем под действием температуры вольфрам из матрицы диффундирует в осмиевый слой и образуется интерметаллическое соединение, после чего 

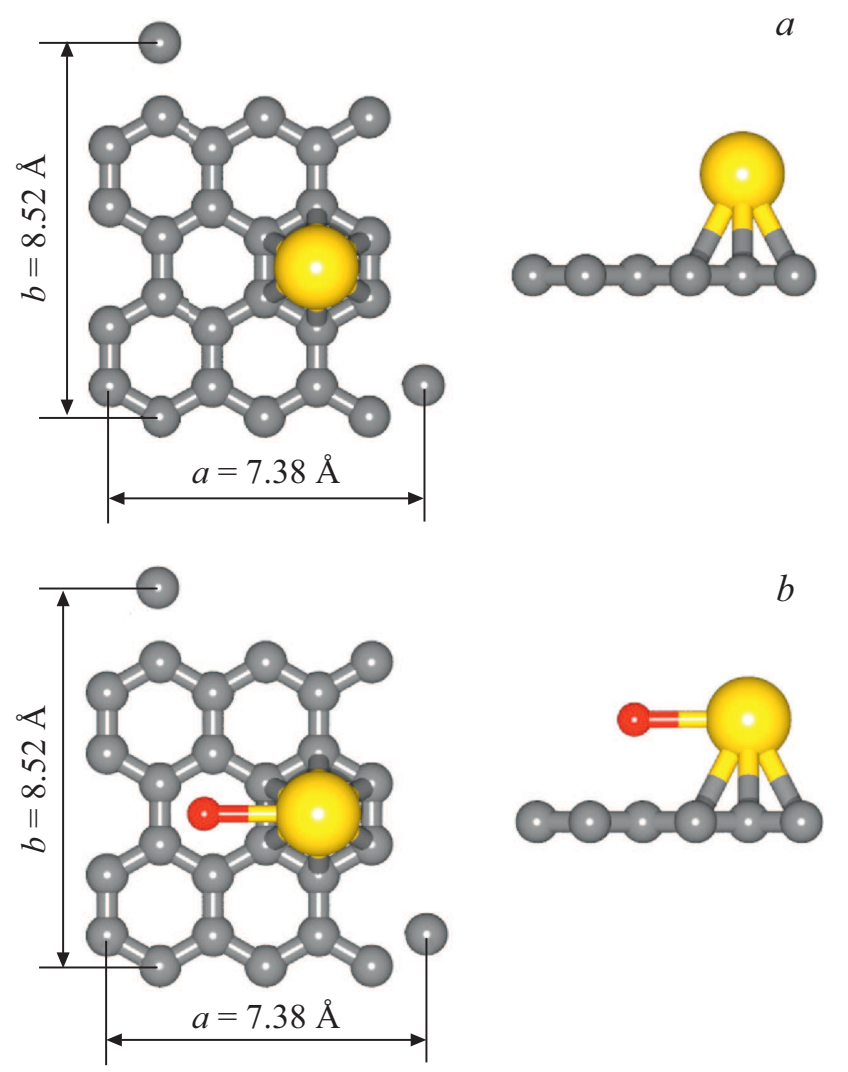

$b$

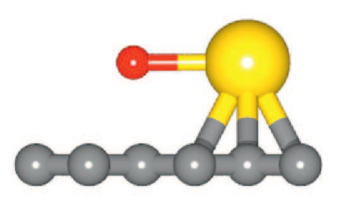

Рис. 1. Общий вид (сверху и сбоку) графеновых наночастиц с присоединенными атомарным барием $(a)$ и молекулой $\mathrm{BaO}(b)$.

работа выхода МПК повышается, и его эмиссионные характеристики снижаются.

Для устранения указанных недостатков для катодов сверхдолговечных ламп бегущей волны (ЛБВ) предлагается использовать модификацию МПК наноуглеродными частицами: Астраленами( $)$ и сульфоаддуктом нанокластеров углерода (Углероном ( ).

В работах $[4,5]$ уже сообщалось о положительных результатах испытаний на долговечность катодов, модифицированных наноуглеродом, в диодном режиме (предположительно за счет снижения скорости испарения активного вещества - алюмината бария-кальция - и снижения работы выхода электронов). В частности, было отмечено снижение количества активного элемента (Ва) на эмиссионной поверхности модифицированного катода, а также значительно меньшее количество напыленных с катода активных элементов Ва и О на поверхности анода, чем для типового катода, но механизм влияния углеродных нанокластеров на работу МПК был изучен недостаточно.

Цель настоящей работы состоит в теоретическом обосновании улучшенных эмиссионных свойств МПК, модифицированных наноуглеродом, а также в их проверке в вакуумных условиях реального прибора.

Известно, что Углерон( - это неупорядоченное множество графеновых листов, а Астрален® - мно- гослойный тор, состоящий из свернутых графеновых листов, находящихся друг в друге. Для объяснения результатов, полученных в работе [4], было проведено моделирование взаимодействия моно- и бислойного графена с барием и оксидом бария. Графеновый лист состоял из 24 атомов углерода. Оптимизация с помощью $16 \times 16 \times 1$-разбиения зоны Бриллюэна по схеме Монкхорста-Пака проводилась в рамках метода DFT (density functional theory) в программном пакете Quantum-Espresso [6]. В ходе оптимизации рассматриваемые структуры помещались в периодический ящик с векторами трансляции $a=7.38 \AA, b=8.52 \AA$. Общий вид равновесной конфигурации графена и бислойного графена с присоединенными функциональными группами Ва и $+\mathrm{BaO}$ представлен на рис. 1 и 2.

Энтальпия реакции образования связи $\Delta H_{f}$ и энергия связи $E_{\text {bind }}$ между графеном и барием определялись по формулам [7]:

$$
\begin{gathered}
\Delta H_{f}=E\left(\text { graphene }+\mathrm{Ba}_{\text {opt }}\right)-E\left(\text { graphene }_{\text {opt }}\right)-E(\mathrm{Ba}), \\
E_{\text {bind }}=E\left(\text { graphene }+\mathrm{Ba}_{\text {opt }}\right)-E(\text { graphene })-E(\mathrm{Ba}) .
\end{gathered}
$$

Аналогично рассчитывались параметры для взаимодействия графена с оксидом бария, а также бислойного графена с барием и оксидом бария. Полученные результаты приведены в табл. 1. Из этой таблицы следует, что модуль энтальпии реакции образования соединения бислойного графена с барием и молекулой $\mathrm{BaO}$ значительно выше, чем у монослойного. Это свидетельствует
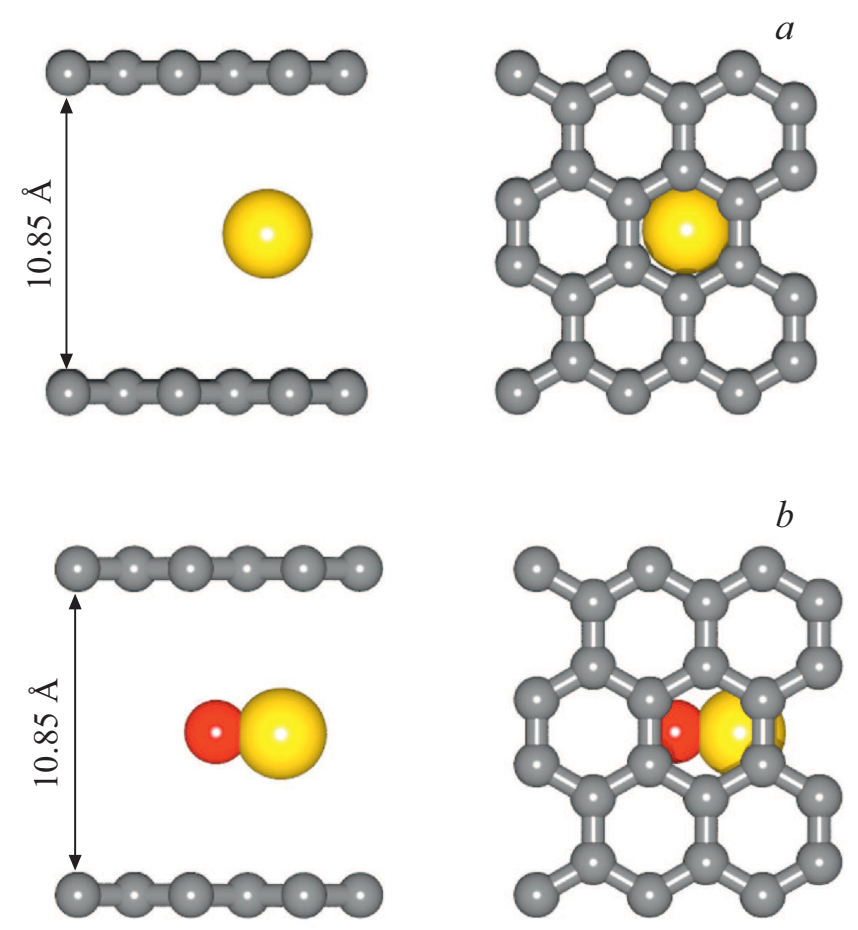

Рис. 2. Общий вид (сверху и сбоку) бислойных графеновых наночастиц с присоединенными атомарным барием $(a)$ и молекулой $\mathrm{BaO}(b)$. 
Таблица 1. Энтальпия реакции образования связи и энергия связи между моно- и бислойным графеном с присоединенными функциональными группами $-\mathrm{Ba}$ и $-\mathrm{BaO}$

\begin{tabular}{l|c|c|c|c}
\hline \multicolumn{1}{c|}{ Параметр } & Графен $+\mathrm{Ba}$ & Графен $+\mathrm{BaO}$ & $\begin{array}{c}\text { Бислойный } \\
\text { графен }+\mathrm{Ba}\end{array}$ & $\begin{array}{c}\text { Бислойный } \\
\text { графен }+\mathrm{BaO}\end{array}$ \\
\hline Энтальпия реакции & -0.0892 & -0.0025 & -0.2048 & -0.0067 \\
образования связи, $\mathrm{eV}$ & -0.0874 & -0.0018 & -0.2024 & -0.0056
\end{tabular}

Таблица 2. Работа выхода исследуемых структур

\begin{tabular}{l|c}
\multicolumn{1}{c|}{ Структура } & Работа выхода, $\mathrm{eV}$ \\
\hline Графен & 4.66 \\
Графен $+\mathrm{Ba}$ & 2.77 \\
Графен $+\mathrm{BaO}$ & 3.51 \\
Бислойный графен & 3.17 \\
Бислойный графен $+\mathrm{Ba}$ & 1.88 \\
Бислойный графен $+\mathrm{BaO}$ & 2.65
\end{tabular}

о том, что образование соединений бария и оксида бария с бислойным графеном является энергетически более выгодным, чем с монослойным. Следовательно, функциональным группам - Ва и $-\mathrm{BaO}$ выгоднее находиться в полости наноуглеродных частиц (в частности, Углерона®), чем на его поверхности. Кроме того, абсолютное значение энергии связи бислойного графена с барием и молекулой $\mathrm{BaO}$ выше, чем у монослойного. Это указывает на то, что связь атомарного бария и молекулы $\mathrm{BaO}$ с бислойным графеном прочнее, чем с монослойным; следовательно, чтобы разорвать связь бария с бислойным графеном, потребуется гораздо бо́льшая энергия.

Для подтверждения данных выводов была экспериментально определена скорость испарения активного вещества с поверхности катодов с типовым и модифицированным барий-кальциевым алюминатом с Углероном® при помощи пьезокварцевого взвешивания и метода Беккера. Эксперименты показали снижение скорости испарения для модифицированного активного вещества примерно в 1.5 раза.

Кроме того, был проведен расчет зонных структур моно- и бислойного графена с добавлением бария и оксида бария. На основании проведенных расчетов по величине энергии Ферми оценивалась работа выхода (табл. 2). На рис. 3 отчетливо видно смещение уровня Ферми для структуры бислойный графен $+\mathrm{Ba}$ относительно уровня Ферми чистого бислойного графена (с -3.17 до $-1.88 \mathrm{eV})$. Из табл. 2 следует, что адсорбция бария и оксида бария на монослойном и бислойном графене приводит к снижению работы выхода до значений, которые существенно ниже работы выхода наноуглеродных структур без адатомов и известного значения работы выхода классического углерода.
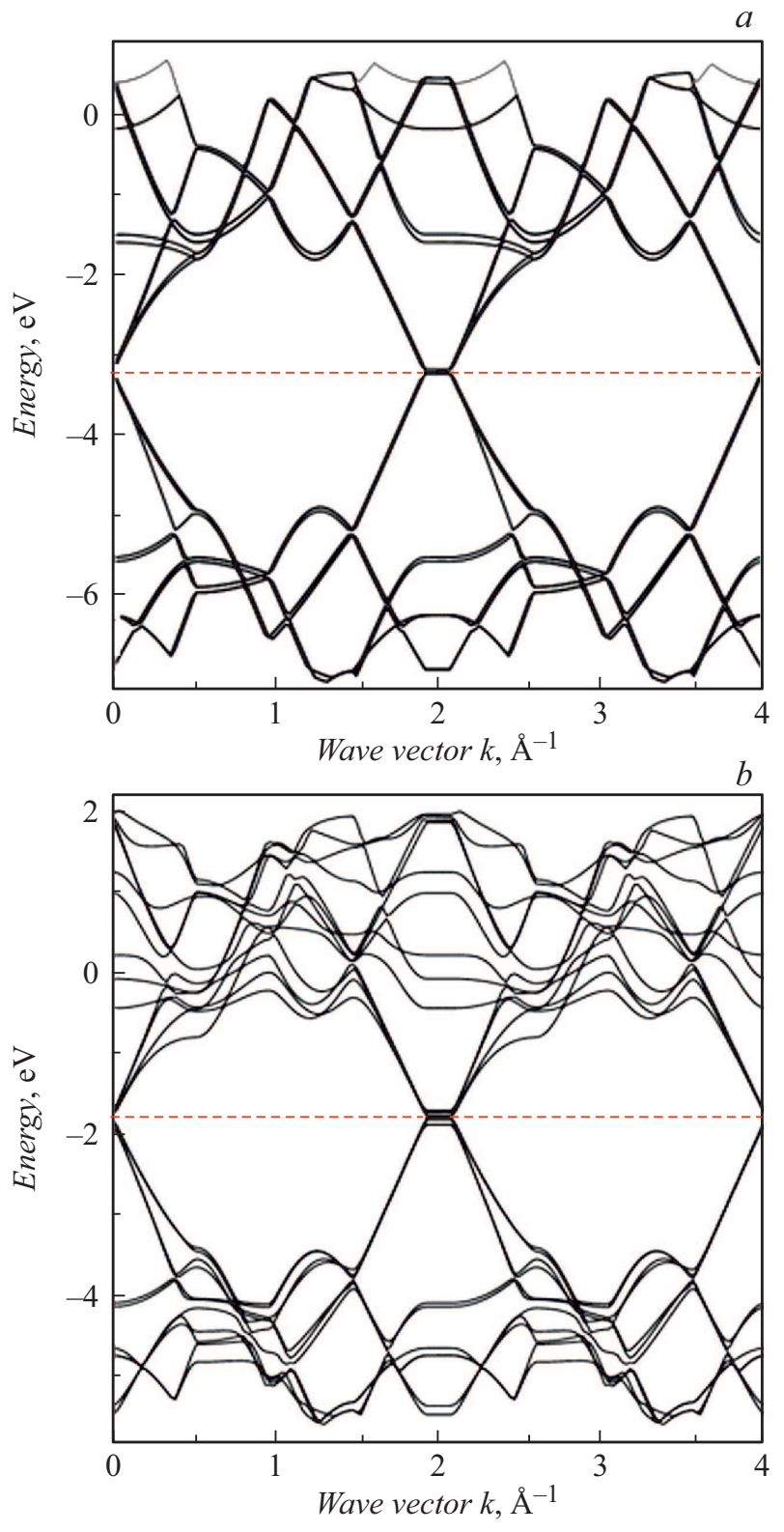

Рис. 3. Зонная структура бислойного графена $(a)$ и бислойного графена, допированного барием $(b)$. Штриховые линии указывают положение уровня Ферми.

В работе [8] также указано на особенности зонных

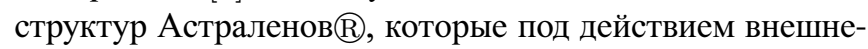
го электрического поля будут препятствовать диффузии 
вольфрама в пленку осмия в процессе эксплуатации катода, а также его отравлению, что приведет к повышению срока службы.

На последнем этапе были исследованы эмиссионные параметры опытной ЛБВ с катодом, изготовленным по разработанной технологии с Астраленами® и Углероном( с покрытием пленкой состава Os-Ir-Al без подпитывающей камеры. Сравнение характеристик с серийными приборами показало, что ток катода, изготовленного по новой технологии, при рабочей температуре $1213 \mathrm{~K}$ (яркостной), равной рабочей температуре типового катода, на $10 \%$ выше, чем у типового. Перед постановкой на ускоренные испытания долговечности прибор успешно прошел $325 \mathrm{~h}$ прогона при пониженной температуре $1203 \mathrm{~K}$ (яркостной) по технологии ЛБВ с типовым катодом согласно методике [9] для прогнозирования индивидуальной долговечности конкретного катода в вакуумных условиях данного прибора.

В настоящий момент экспериментальный прибор имеет наработку $1700 \mathrm{~h}$. Температура катода при ускоренных испытаниях превышает рабочую на $270 \mathrm{~K}$, что соответствует коэффициенту ускорения 1024. Эмиссионная характеристика прибора удовлетворяет критериям годности: спад тока в рабочей точке не более 5\%. По данным эксперимента, после наработки в режиме ускоренных испытаний $1700 \mathrm{~h}$ спад тока в рабочей точке равен нулю, что соответствует ресурсной долговечности катода при плотности тока $0.645 \mathrm{~A} / \mathrm{cm}^{2}$ в составе ЛБВ более 1740800 h. Испытания продолжаются.

\section{Конфликт интересов}

Авторы заявляют, что у них нет конфликта интересов.

\section{Список литературы}

[1] Воронин В.И. Откачка электровакуумных приборов камерным и гнездовым способами / Под ред. Г.В. Конюшкова. Саратов: Сарат. гос. техн. ун-т, 2010. 176 с.

[2] Диспенсерные катоды с прогнозируемым сроком службы более 20 лет // Новости СВЧ-техники. 2015. № 6. С. 22-27.

[3] Green M.C., Skiner H.B., Tuck B.A. // Appl. Surf. Sci. 1981. V. 8. P. 13-35.

[4] Крачковская T.М., Сторублев А.В., Сахаджси Г.В., Емельянов А.С. // Изв. вузов России. Радиоэлектроника. 2018. № 4. C. 57-63. DOI: 10/32603/1993-8985-2018-21-4-57-63

[5] Крачковская Т.М., Мельников Л.А. // Письма в ЖТФ. 2018. T. 44. B. 22. C. $11-18$. DOI: 10.21883/PJTF.2018.22.46916.17460

[6] Giannozzi P., Baroni S., Bonini N., Calandra M., Car R., Cavazzoni C., Ceresoli D., Chiarotti G.L., Cococcioni M., Dabo I. // J. Phys.: Condens. Matter. 2009. V. 21. P. 395502. DOI: $10.1088 / 0953-8984 / 21 / 39 / 395502$

[7] Shunaev V.V., Glukhova O.E. // J. Phys. Chem. C. 2016. V. 120. P. 4145-4149. DOI: 10.1021/acs.jpcc.5b12616

[8] Shames A.I., Katz E.A., Panich A.M., Mogilyansky D., Mogilko E., Grinblat J., Belousov V.P., Belousova I.M., Ponomarev A.N. // Diamond Relat. Mater. 2009. V. 18. P. 505510. DOI: $10.1016 /$ j.diamond.2008.10.056
[9] Ворожсейкин В.Г., Дудкин В.Н., Набоков Ю.И. Способ прогнозирования индивидуальной долговечности электровакуумных приборов. Патент № 1277821 RU. Опубл.: 06.10.2000. 